\title{
FREQUENCY OF OSCILLATIONS OF A SYNCHRONOUS MOTOR
}

1. Introduction. In this paper we consider the differential equation

$$
\ddot{\theta}+\sin \theta-\sin \theta_{0}=0,
$$

in which $\theta_{0}$ is a given constant from the open interval $(0, \pi / 2)$, and $\theta=\theta(t)$ is the unknown function. Equation (1.1) occurs in the theory of a synchronous motor as a special case of the more general equation

$$
\ddot{\theta}+f(\theta) \dot{\theta}+g(\theta)=D,
$$

for the power angle $\theta(t)$ as a function of time. Here, $g(\theta)$ and $f(\theta)$ are some known periodic functions with period $2 \pi$, and represent the electrodynamical torque and the damping coefficient of the motor, respectively. The quantity $D$ may be considered as the external moment (cf. [5], 5.101; [7], 6.3 and also the references in those works).

In recent years some essential results in the qualitative theory of equation (1.2) have been obtained. Those results explain some effects during the motion of a synchronous motor, noticed empirically (see [2], p.16-21; [6], p.190-191; [14], p. 66-80; [1], VII, § 2, §3). A quantitative analysis of the equation (1.2) is rather less developed ([5], 5. 102; [8], VIII, 8.30-8.43; [9], § 4).

The point $\theta=\theta_{0}$ is a point of stable equilibrium of equation (1.1). If the deflection $\delta=\theta(t)-\theta_{0}$ from the equilibrium-point is sufficiently small, equation (1.1) may be approximated by

$$
\ddot{\delta}+\left(\cos \theta_{0}\right) \delta=0 \text {. }
$$

Then, for the frequency $\omega$ of the free oscillations of the power angle we have the well-known formula

$$
\omega^{2}=\cos \theta_{0} \text {. }
$$

However, that formula cannot be used for large amplitudes of oscillations defined by

$$
a=\frac{1}{2}(\max \theta-\min \theta) .
$$


In that case, one considers higher terms in the power expansion of $\sin \theta$ $=\sin \left(\theta_{0}+\delta\right)$ in order to get the approximate equation

$$
\ddot{\delta}+\left(\delta-\frac{1}{6} \delta^{3}\right) \cos \theta_{0}-\frac{1}{2} \delta^{2} \sin \theta_{0}=0
$$

within the third degree of accuracy. The study of the dependence between the amplitude, the frequency of oscillations and the parameter $\theta_{0}$ involves elliptic functions. In this way a formula more accurate than (1.3) could be obtained. Here we are going to follow another direction of investigation.

Suppose that the solution $\theta=\theta(t)$ of equation (1.1) describes the vibrations about the equilibrium-point $\theta_{0}$. Denote

$$
\theta_{1}=\min \theta(t), \quad \theta_{2}=\max \theta(t) .
$$

Then, the period of the oscillations $T$ is given by

$$
T=\sqrt{2} \int_{\theta_{1}}^{\theta_{2}}\left[\left(\cos \theta-\cos \theta_{1}\right)+\left(\theta-\theta_{1}\right) \sin \theta_{0}\right]^{-1 / 2} d \theta,
$$

(cf. [4], § 42). Finally, let $\omega=2 \pi / T$ be the corresponding circular frequency of the oscillations. In this paper some approximate formulae for $\omega$ as well as the estimates for the error of approximation will be given. The methods are based on papers [10], [11], [12].

2. Range of oscillations. Denote by $g(\theta)$ and $G(\theta)$ the control-function and the potential energy, respectively. In the case of equation (1.1) we have

$$
g(\theta)=\sin \theta-\sin \theta_{0}
$$

and

$$
G(\theta)=\int_{\theta_{0}}^{\theta} g(0) d \theta=-\cos \theta+\cos 0_{0}-\left(\theta-\theta_{0}\right) \sin \theta_{0} .
$$

From Fig. 1 and also [4], $\$ 42$ it can be seen that the quantity $\theta_{1}$ defined by (1.5) satisfies the conditions

and

or, by (2.2),

$$
-\pi-\theta_{0}<\theta_{1}<\theta_{0}
$$

$$
G\left(0_{1}\right)<G\left(\pi-\theta_{0}\right)
$$

On the other hand, if $\theta_{1}$ satisfies (2.3) and (2.4') there exists a periodic solution $\theta=\theta(t)$ of the initial-value problem

$$
\begin{gathered}
\ddot{\theta}+\sin 0-\sin \theta_{0}=0, \\
\theta(0)=\theta_{1}, \quad \dot{\theta}(0)=0,
\end{gathered}
$$


describing the oscillations about the equilibrium-point $\theta_{0}$. Of course, $\theta_{1}$ is the left turning point of those oscillations.

Given the left turning-point $\theta_{1}$ we find the right turning-point $\theta_{2}$ by standard methods from the equation $G\left(\theta_{2}\right)=G\left(\theta_{1}\right)$ (cf. [4], § 42). In this way we obtain the transcendental equation

$$
\cos \theta_{2}-\cos \theta_{1}+\left(\theta_{2}-\theta_{1}\right) \sin \theta_{0}=0,
$$

where the solution $\theta_{0}<\theta_{2}<\pi-\theta_{0}$ is needed in our case. Obviously, the required solution of equation (2.6) exists provided conditions (2.3) and (2.4') hold (see Fig. 1).

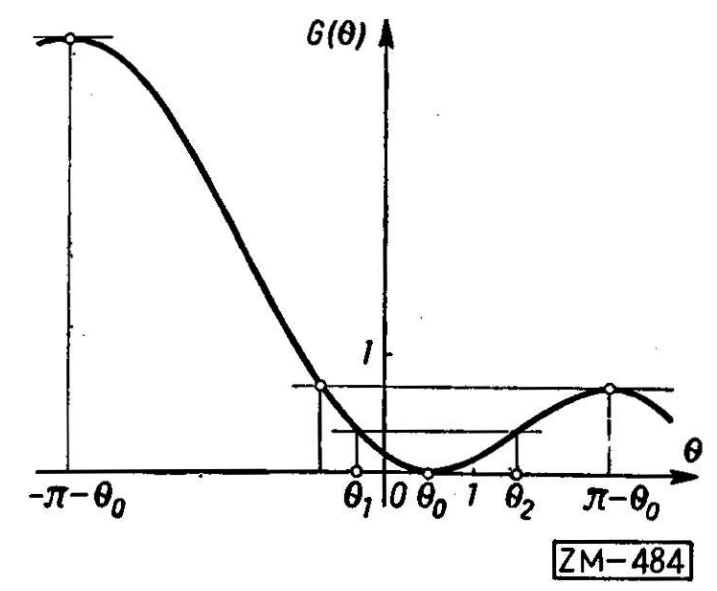

Fig. 1. Case $\theta_{0}=0,5 ; \theta_{1}=-0,3$

Now we give a method of finding $\theta_{2}$. We first find the dependence between the quantities $\theta_{1}, \theta_{2}$ and the amplitude

$$
a=\frac{\theta_{2}-\theta_{1}}{2}
$$

of the oscillations. Accordingly put

$$
\theta_{1}=q-a, \quad \theta_{2}=q+a .
$$

By substituting these expressions in (2.6) we obtain the equation

$$
\sin q=\frac{a \sin \theta_{0}}{\sin a}
$$

Next we define two sequences $\left\{a^{(n)}\right\}$ and $\left\{g^{(n)}\right\}$ by the formulae

$$
\begin{gathered}
a^{(0)}=+0, \quad q^{(n)}=\arcsin \frac{a^{(n)} \sin \theta_{0}}{\sin a^{(n)}}, \\
a^{(n+1)}=q^{(n)}-\theta_{1}, \quad n=0,1,2, \ldots
\end{gathered}
$$


It can be proved that:

(i) there exist $\lim _{n \rightarrow \infty} q^{(n)}$ and $\lim _{n \rightarrow \infty} a^{(n)}$,

(ii) $\theta_{2}=\lim _{n \rightarrow \infty}\left[q^{(n)}+a^{(n)}\right]$

if (2.3) and (2.4') hold. Here is the plan of the proof:

1. We show that the graphs of the functions $y=a \sin \theta_{0} / \sin a$ and $y=\sin \left(a+\theta_{1}\right)$ are located as in Fig. 2 .

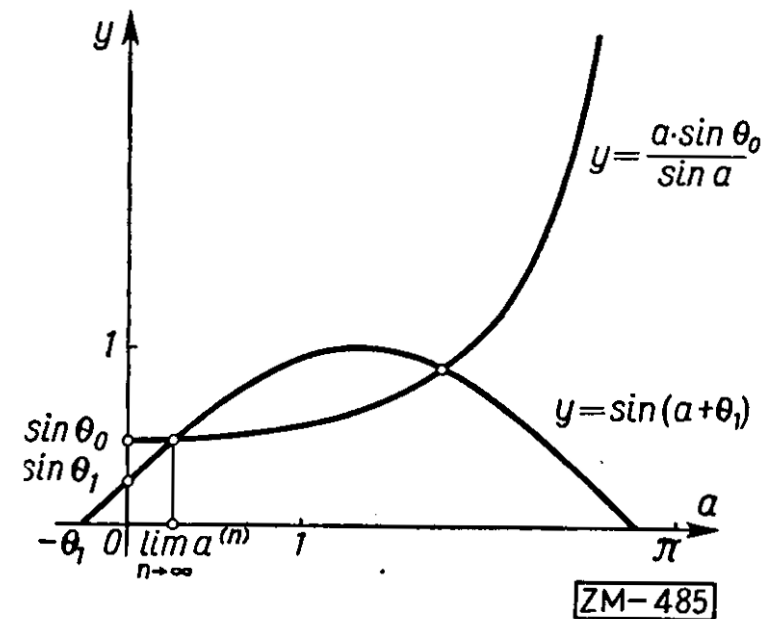

Fig. 2. Case $\theta_{0}=0,5 ; \theta_{1}=0,25$

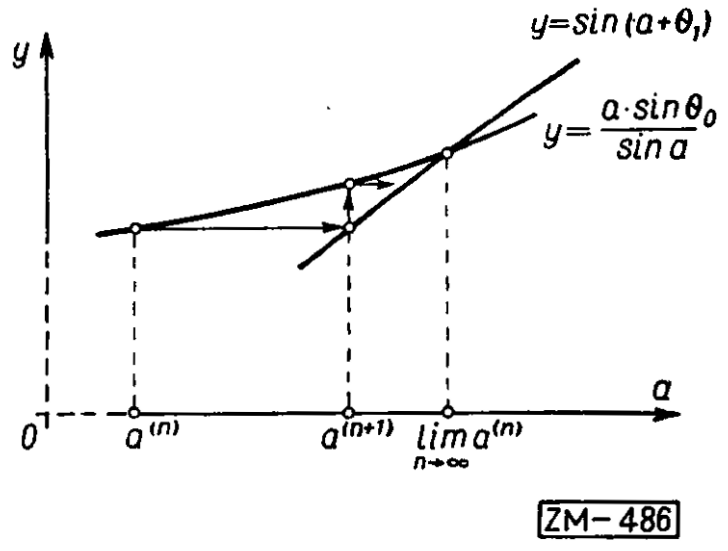

Fig. 3

2. We verify that

$$
a^{(n)}<a^{(n+1)}<a, \quad q^{(n)}<q^{(n+1)}<q
$$

(see Fig. 3), from which (i) follows. Then the quantity $\bar{\theta}_{2}=\lim _{n \rightarrow \infty}\left[q^{(n)}+\right.$ $\left.+a^{(n)}\right]$ satisfies equation (2.6) and the inequality $\theta_{0}<\bar{\theta}_{2}<\pi-{ }_{n}^{n \rightarrow \infty}$. Since there exists only one root of (2.6) in the interval $\left(\theta_{0}, \pi-\theta_{0}\right)$, we obtain (ii). The details of the proof are omitted. Relation (ii) gives a simple rule to find $\theta_{2}$ with any required numerical accuracy.

3. Auxilary control-functions. In the initial value problem (2.5) the control-function $g(\theta)=\sin \theta-\sin \theta_{0}$ is non-odd with regard to the point of equilibrium $\theta_{0}$. The problem may be replaced by two similar problems with odd control-functions

$$
\begin{aligned}
& g_{1}(\delta)=-\operatorname{sgn} \delta \cdot g\left(\theta_{0}-|\delta|\right), \\
& g_{\mathbf{z}}(\delta)=\operatorname{sgn} \delta \cdot g\left(\theta_{0}+|\delta|\right) .
\end{aligned}
$$

Then $g\left(0_{0}+\delta\right)=g_{1}(\delta)$ for $\delta \leqslant 0$ and $g\left(\theta_{0}+\delta\right)=g_{\mathbf{g}}(\delta)$ for $\delta \geqslant 0$ and instead of the initial problem (2.5) we can consider the following initial value problems:

$$
\begin{gathered}
\ddot{\delta}+g_{1}(\delta)=0, \\
\delta(0)=\theta_{1}-\theta_{0}, \quad \dot{\delta}(0)=0
\end{gathered}
$$


and

$$
\begin{gathered}
\ddot{\delta}+g_{2}(\delta)=0, \\
\delta(0)=\theta_{2}-\theta_{0}, \quad \dot{\delta}(0)=0 .
\end{gathered}
$$

Put

$$
a_{1}=\theta_{0}-\theta_{1}, \quad a_{2}=\theta_{2}-\theta_{0} .
$$

In view of the inequalities $-\pi-\theta_{0}<\theta_{1}<\theta_{0}$ and $\theta_{0}<\theta_{2}<\pi-\theta_{0}$, by (3.1), we get

$$
\delta \cdot g_{i}(\delta)>0 \quad \text { for } \quad 0<|\delta| \leqslant a_{i} .
$$

Thus the initial-value problems (3.2) and (3.3) have periodic solutions describing the oscillations about the point $\delta=0$ with the amplitudes $a_{1}$ and $a_{2}$, respectively (see $[4], \S 42$ ).

Denote by $T_{1}$ and $T_{2}$ the periods of those oscillations. It is easy to prove that

$$
T=\frac{1}{2}\left(T_{1}+T_{2}\right)
$$

where $T$ is given by formula (1.6).

Put

$$
\omega=\frac{2 \pi}{T}, \quad \omega_{1}=\frac{2 \pi}{T_{1}}, \quad \omega_{2}=\frac{2 \pi}{T_{2}}
$$

and suppose that

$$
\omega_{1} \approx \omega_{1}^{\prime}, \quad \omega_{2} \approx \omega_{2}^{\prime},
$$

where $\omega_{1}^{\prime}$ and $\omega_{2}^{\prime}$ are any approximations of $\omega_{1}$ and $\omega_{2}$. Let $\omega^{\prime}$ be defined by the equation

$$
\frac{1}{\omega^{\prime}}=\frac{1}{2}\left(\frac{1}{\omega_{1}^{\prime}}+\frac{1}{\omega_{2}^{\prime}}\right) .
$$

This yields an approximation $\omega \approx \omega^{\prime}$ with the following estimate for the error:

$$
\frac{\left|\omega-\omega^{\prime}\right|}{\omega} \leqslant \frac{\omega_{2}^{\prime}}{\omega_{1}^{\prime}+\omega_{2}^{\prime}} \cdot \frac{\left|\omega_{1}-\omega_{1}^{\prime}\right|}{\omega_{1}}+\frac{\omega_{1}^{\prime}}{\omega_{1}^{\prime}+\omega_{2}^{\prime}} \cdot \frac{\left|\omega_{2}-\omega_{2}^{\prime}\right|}{\omega_{2}} .
$$

In fact, by (3.5) and (3.6) we have

$$
\frac{1}{\omega}=\frac{1}{2}\left(\frac{1}{\omega_{1}}+\frac{1}{\omega_{2}}\right)
$$

and by (3.8) it follows that

$$
\frac{\omega-\omega^{\prime}}{\omega}=\frac{\omega_{2}^{\prime}}{\omega_{1}^{\prime}+\omega_{2}^{\prime}} \cdot \frac{\omega_{1}-\omega_{1}^{\prime}}{\omega_{1}}+\frac{\omega_{1}^{\prime}}{\omega_{1}^{\prime}+\omega_{2}^{\prime}} \cdot \frac{\omega_{2}-\omega_{2}^{\prime}}{\omega_{2}},
$$

which implies (3.9). 
4. The approximations for $\omega_{1}$ and $\omega_{2}$. The considerations of the preceding sections permit the use of the well-known approximate formulae

$$
\omega_{i}^{2} \approx\left(\omega_{i}^{\prime}\right)^{2}=\frac{1}{\pi a_{i}} \int_{0}^{2 \pi} g_{i}\left(a_{i} \sin \alpha\right) \sin \alpha d a
$$

obtained by asymptotic methods (cf. [3], $\$ 2$ ). In those formulae the functions $g_{i}$ are given by (3.1) and $a_{i}$ are the amplitudes of the oscillations determined by (3.2), (3.3) and (3.4) (see [10]; [11], § 1, §4).

In view of (2.1) and (3.1), we obtain for $g_{i}(\delta)$ the following expressions:

$$
g_{i}(\delta)=\sin \delta \cos \theta_{0}-(-1)^{i} \operatorname{sgn} \delta \cdot(1-\cos \delta) \sin \theta_{0} ; \quad i=1,2 .
$$

Substituting (4.2) in (4.1), we get

$$
\begin{aligned}
&\left(\omega_{i}^{\prime}\right)^{2}=\left(\pi a_{i}\right)^{-1} \cos \theta_{0} \int_{0}^{2 \pi} \sin \left(a_{i} \sin \alpha\right) \sin \alpha d \alpha- \\
&-(-1)^{i}\left(\pi a_{i}\right)^{-1} \sin \theta_{0} \int_{0}^{2 \pi}\left[1-\cos \left(a_{i} \sin \alpha\right)\right]|\sin \alpha| d \alpha .
\end{aligned}
$$

After calculations with the use of integral tables ([13], 3.524.5; 3.524.3) we get the following expressions:

$$
\left(\omega_{i}^{\prime}\right)^{2}=A_{1}\left(a_{i}\right) \cos \theta_{0}-(-1)^{i} A_{2}\left(a_{i}\right) \sin \theta_{0}
$$

where

$$
A_{1}(a)=\frac{2 J_{1}(a)}{a}=\sum_{n=0}^{\infty}(-1)^{n} \frac{a^{2 n}}{2^{2 n} n !(n+1) !}
$$

$$
A_{2}(a)=\frac{4}{\pi} \sum_{n=0}^{\infty}(-1)^{n} \frac{a^{2 n+1}}{(2 n+1) ! !(2 n+3) ! !}
$$

We thus have the required approximations for $\omega_{1}$ and $\omega_{2}$.

In [12], $\$ 3$, the estimates of the errors

have been found as

$$
e_{i}=\frac{\omega_{i}^{\prime}-\omega_{i}}{\omega_{i}}
$$

$$
0 \leqslant e_{i} \leqslant 0,43 \varrho_{i}^{5 / 2} \omega_{i}^{\prime}\left(\Omega_{i}^{4}-\omega_{i}^{\prime 4}\right),
$$

where

$$
\Omega_{i}^{4}=\frac{1}{\pi a_{i}^{2}} \int_{0}^{2 \pi} g_{i}^{2}\left(a_{i} \sin \alpha\right) d \alpha,
$$

and the constants $\varrho_{i}$ will be given later. (In [12] an other notation was used: $g_{i}=g, \varrho_{i} \equiv r^{-1}, \omega_{i}^{\prime} \equiv \omega_{\mathrm{ag}}$ and $\Omega_{i} \equiv \omega_{\mathrm{op}}$ ) 
By substituting (4.2) in (4.5) we have

(4.6) $\Omega_{i}^{4}=B_{11}\left(a_{i}\right) \cos ^{2} \theta_{0}-(-1)^{i} 2 B_{12}\left(a_{i}\right) \sin \theta_{0} \cos \theta_{0}+B_{22}\left(a_{i}\right) \sin ^{2} \theta_{0}$,

where we write

$$
\begin{aligned}
& B_{11}(a)=\frac{1}{\pi a^{2}} \int_{0}^{2 \pi} \sin ^{2}(a \sin \alpha) d \alpha \\
& B_{22}(a)=\frac{1}{\pi a^{2}} \int_{0}^{2 \pi}[1-\cos (a \sin \alpha)]^{2} d \alpha, \\
& B_{12}(a)=\frac{1}{\pi a^{2}} \int_{0}^{2 \pi}[1-\cos (a \sin \alpha)] \sin |a \sin \alpha| d \alpha .
\end{aligned}
$$

These integrals, by well-known formulae (cf. [13], 3.528,3; 3.421.1), are equal to:

$$
\begin{aligned}
& B_{11}(a)=\frac{1}{a^{2}}\left[1-J_{0}(2 a)\right], \\
& B_{22}(a)=\frac{1}{a^{2}}\left[3-4 J_{0}(a)+J_{0}(2 a)\right], \\
& B_{12}(a)=\frac{4}{\pi} \sum_{n=0}^{\infty}(-1)^{n} \frac{4^{n+1}-1}{[(2 n+3) ! !]^{2}} a^{2 n+1} .
\end{aligned}
$$

Then, by (4.6) and (4.7) we calculate $\Omega_{i}$.

Now, the constants $\varrho_{i}$ in (4.4) are (see [12], § 2)

where

$$
\varrho_{i}=\frac{1}{2} \sup _{\left(0, a_{i}\right)} \frac{a_{i}^{2}-x^{2}}{G_{i}\left(a_{i}\right)-G_{i}(x)}, \quad i=1,2
$$

$$
G_{i}(x)=\int_{0}^{x} g_{i}(x) d x
$$

From the expression for $g_{2}(x)$, by (4.2), it can be verified that $g_{2}(x)$ represents a soft control-function. In this case the equality

$$
\sup _{\left(0, a_{2}\right)} \frac{a_{2}^{2}-x^{2}}{G_{2}\left(a_{2}\right)-G_{2}(x)}=\lim _{x \rightarrow a_{2}} \frac{a_{2}^{2}-x^{2}}{G_{2}\left(a_{2}\right)-G_{2}(x)}
$$

holds (see [11], §4). Hence

$$
\varrho_{2}=\frac{a_{2}}{\sin 0_{2}-\sin \theta_{0}} .
$$


The determination of $\varrho_{1}$ may be more involved. If $a_{1} \leqslant \theta_{0}$, the function $g_{1}(x)$ represents a hard control-function in the interval $\left\langle-a_{1}, a_{1}\right\rangle$. Therefore

$$
\sup _{\left(0, a_{1}\right)} \frac{a_{1}^{2}-x^{2}}{G_{1}\left(a_{1}\right)-G_{1}(x)}=\lim _{x \rightarrow 0} \frac{a_{1}^{2}-x^{2}}{G_{1}\left(a_{1}\right)-G_{1}(x)}
$$

(see [11], §4) and by (4.8) and (4.2) we have

$$
\varrho_{1}=\frac{a_{1}^{2}}{2\left(\cos \theta_{0}-\cos \theta_{1}+a_{1} \sin \theta_{0}\right)} .
$$

If $a_{1}>\theta_{0}$, the function $\left(a_{1}^{2}-x^{2}\right) /\left[G_{1}\left(a_{1}\right)-G_{1}(x)\right]$ may attain its maximal value at an interior point of the interval $\left\langle-a_{1}, 0\right\rangle$. Then it is necessary to solve a transcendental equation. In this case, however, instead of determining $\varrho_{1}$ we can use the inequality

$$
\varrho_{1} \leqslant \frac{a_{1}}{2 \sin \frac{1}{2} a_{1} \min \left[\cos \theta_{0}, \cos \left(\theta_{0}-\frac{1}{2} a_{1}\right)\right]},
$$

which follows simply from the estimate

$$
\sup _{\left(0, a_{1}\right)} \frac{a_{1}^{2}-x^{2}}{G_{1}\left(a_{1}\right)-G_{1}(x)} \leqslant \sup _{\left(0, a_{1}\right)} \frac{2 x}{g_{1}(x)} .
$$

In this way we have prepared all the formulae needed for finding the approximate values of $\omega_{1}$ and $\omega_{2}$, and for estimating the errors.

5. Numerical example. As an illustration of the method given in the preceding sections let us assume in the initial-value problem (2.5) the following numerical data:

$$
\theta_{0}=0,5, \quad \theta_{1}=0,25 .
$$

First we check that conditions (2.3) and (2.4') hold. Thus the initialvalue problem (2.5) has a periodic solution.

In order to estimate the corresponding cyclic frequency $\omega$ we calculate the right turning-point of the oscillations, using the iteration-process (2.9) for example. Substituting the numerical values (5.1) we find

$$
a^{(5)}=0,256024, \quad q^{(5)}=0,506024 .
$$

The next iteration leaves the above six decimals unchanged. Hence, by 2 (ii), we may assume

$$
\theta_{2}=q^{(5)}+a^{(5)}=0,762048
$$

with accuracy $10^{-6}$. Now, from (3.4) we get

$$
a_{1}=0,250000, \quad a_{2}=0,262048
$$


and consequently, by $\left(4.3^{\prime}\right)$, we calculate

$$
\begin{array}{ll}
A_{1}\left(a_{1}\right)=0,9922080, & A_{2}\left(a_{1}\right)=0,1056620, \\
A_{1}\left(a_{2}\right)=0,9914413, & A_{2}\left(a_{2}\right)=0,1107085 .
\end{array}
$$

Using (4.3) we obtain

or

$$
\omega_{1}^{\prime 2}=0,9214015, \quad \omega_{2}^{\prime 2}=0,8169947
$$

$$
\omega_{1}^{\prime}=0,9598966, \quad \omega_{2}^{\prime}=0,9038776 .
$$

Finally formula (3.8) gives

$$
\omega^{\prime}=0,931045 \text {, }
$$

which is an approximation of the frequency $\omega$ of oscillations. In order to estimate the error of that approximation we calculate by (4.7) and (5.3) the numerical values

$$
\begin{array}{ll}
B_{11}\left(a_{1}\right)=0,9844830, & B_{11}\left(a_{2}\right)=0,9829637, \\
B_{12}\left(a_{1}\right)=0,1047841, & B_{12}\left(a_{2}\right)=0,1096985, \\
B_{22}\left(a_{1}\right)=0,0116174, & B_{22}\left(a_{2}\right)=0,0127527 .
\end{array}
$$

Then formula (4.6) yields

$$
\Omega_{1}^{4}=0,8490439, \quad \Omega_{2}^{4}=0,6676539 .
$$

Now, by (5.4), the estimation formulae (4.4) give

$$
0 \leqslant e_{1} \leqslant 0,0000261 \cdot \varrho_{1}^{5 / 2}, \quad 0 \leqslant e_{2} \leqslant 0,0000675 \cdot \varrho_{2}^{5 / 2} .
$$

The numerical values of $\varrho_{i}$ are calculated by substituting in formula (4.9) and (4.10) the numerical data (5.1), (5.2) and (5.3). We get

Hence

$$
\varrho_{1}=1,0954750, \quad \varrho_{2}=1,2426466 \text {. }
$$

$$
0 \leqslant e_{1} \leqslant 0,0000328, \quad 0 \leqslant e_{2} \leqslant 0,0001161 .
$$

Finally, by (5.4), formula (3.9) gives

$$
0 \leqslant \frac{\omega^{\prime}-\omega}{\omega} \leqslant 0,000076
$$

and

$$
\omega=0,931045-\vartheta \cdot 0,000071
$$

where $0 \leqslant \vartheta \leqslant 1$.

More accurate computations performed by the Department of Numerical Methods at Wrockaw University show the quality of the estimate given by (5.8). By the use of the electronic com- 
puter Elliott 803 the values of the integral (1.6) have been tabulated and those computations have shown that for $\theta_{0}=0,5, a=0,256024$,

Consequently

$$
\omega=0,93101815 \text {. }
$$

$$
\omega^{\prime}-\omega=0,000027,
$$

which shows that the actual error is 2,7 times smaller than its estimate given by (5.8).

\section{References}

[1] А. А. Андронов, А. А. Витт, С. Э. Х айкин, Теория колебаний, 2 пвд,, Москва 1959.

[2] G. V. Aronovitch, L. N. Belustina, N. A. Kartvelishvili and Ya. K. Lubimtsev, Application of Oscillatory System Analysis to Stability Problems in the Steady-State Operation of Hydroelectric Stations and Power Systems, Труды международного симповиума по нелинейным нолебаниям, Киев, 1963, vol. 3, pp.9-34.

[3] Н. Н. Боголюбов, Ю. А. Митропольски и, Асимптотинеские методь в теории нелинейных колебаний, 2 ивд., Москва 1958.

[4] H. Kauderer, Nichtlineare Mechanik, Berlin 1958.

[5] K. P. Korács and I. Rácz, Transiente Vorgänge in Wechselstrommaschinen, vol. 1, Budapest 1959.

[6] Y. H. Ku, On Nonlinear Oscillations in Electromechanical Systems, Труды международного симпозиума по нелинейным колебаниям, Киев, vol.3, pp. 180-200.

[7] Th. Laible, Die Theorie der Synchronmaschine im nichtstationären Betrieb, Berlin 1952.

[8] N. W. McLachlan, Ordinary Non-linear Differential Equations, 2nd ed., Oxford 1958.

[9] - Engineering Applications of Nonlinear Theory, Proceedings of the Symposium on Nonlinear Circuit Analysis, Polytechnic Institute of Brooklyn 1956, New York 1957.

[10] A. Rybarski, Angenäherte characteristische Gleichungen der nichtlinearen kconservativen Schwingungssysteme, Bull. Acad. Polon. Sc., Ser. sc. math. astr. et phys., 10 (1962), pp. $519-522$.

[11] - Angenäherte Schwingungsfrequenzformeln für konservative Systeme I, Zastosow. Matem. 7 (1964), pp. 235-253.

[12] - Angenäherte Schwingungsfrequenzformeln für konservative Systeme, II, Zastosow. Matem. 7 (1964), pp. 254- 269.

[13] И. М. Рыжик, И. С. Градштейн, Таблицы интеералов, сумм, рлдов и проивведений, 3 пвд., Москва 1951.

[14] J. J. Stokex, Nonlinear Vibrations in Mechanical and Electrical Systems, New York 1950.

INSTITUTE OF MATHEMATICS, POLISH ACADEMY OF SCIENCES

(INSTYTUT MATEMATYCZNY PAN)

WROCEAW TECHNICAL INSTITUTE, DEPARTMENT OF MATHEMATICS

(POLITRCHNIKA WROCEAWSKA, KATEDRA MATEMATYKI)

Received on 3.8. 1964 
A. RYBARSKI I E. STRZELECKI (Wrockaw)

\section{O CZESTOŚSI DRGAN GENERATORA SYNOHRONICZNEGO}

STRESZOZENIE

W pracy bada się równanie

$$
\ddot{\theta}+\sin \theta-\sin \theta_{0}=0,
$$

gdzie $\theta_{0}$ jest stała należąca do przedziału otwartego $(0, \pi / 2), \theta=\theta(t)$ jest funkcją poszukiwaną. Równanie (1.1) występuje w teorii generatora synchronicznego. Praca zawiera wzory dla przybliżonego obliczania okresu drgań określonych przez równanie (1.1), a także wzory pozwalające oszacować dokładnosć przybliżeń. Na zakończenie podany jest przykład numeryczny.

A. РЫ БА РС КИ Е Е. СТ ПІ ЕЛЕДКИ (Вродпвв)

О ЧАСТОТЕ КОЛЕБАНИЙ СИНХРОННОГО ГЕНЕР АТОРА

P E Э IOM E

В работе ивучается уравнение

$$
\ddot{\theta}+\sin \theta-\sin \theta_{0}=0,
$$

где $\theta_{0}$ является постоянной, принадлежащей к открытому интервалу $(0, \pi / 2)$ а $\theta=\theta(t)$ искомой функцией. Уравнение әто встречается в теории синхронного генератора. Приводнтся формулы для приближенного вычисления частоты колебаний определяемых уравнением (1.1) а также формулы, позволяющие оценить точность получаемых приближений. Работа заканчивается численным примером. 